IP $\rightleftharpoons$ B

\title{
Controle químico de plantas daninhas em povoamentos de restauração florestal
}

\author{
Flávio Augusto Monteiro dos Santos ${ }^{1}$ (D) , Paulo Sérgio dos Santos Leles ${ }^{1}$ (D), João Elves da Silva Santana ${ }^{1 *(D)}$, Daniel Ferreira do Nascimento²(D), \\ Aroldo Ferreira Lopes Machado ${ }^{1}$ (D)
}

${ }^{1}$ Universidade Federal Rural do Rio de Janeiro, BR 465, Km 7, CEP 23890-000, Seropédica, RJ, Brasil

${ }^{2}$ PCH Santa Rosa II, Rua Alberto Lamego, 615 - casa 33, Horto, CEP 280015-620, Campos dos Goytacazes, RJ, Brasil

*Autor correspondente:

joao-elvis@outlook.com

Termos para indexação:

Glifosato

Espécie nativa

Conservação da floresta

Index terms:

Glyphosate

Native species

Forest conservation

Histórico do artigo:

Recebido em 07/11/2017

Aceito em 17/12/2018

Publicado em 29/12/2018

doi: 10.4336/2018.pfb.38e201701524

\begin{abstract}
Resumo - Objetivou-se avaliar o emprego do tratamento químico, com herbicida a base de glifosato, na formação de povoamentos de restauração florestal em áreas com predominância de braquiária, em comparação ao controle mecânico. O tratamento químico foi realizado através de capina em faixas de 1,2 $\mathrm{m}$, antes do plantio, e quando a braquiária apresentava altura média de $30 \mathrm{~cm}$, aplicando-se glifosato na dose de 1,44 $\mathrm{kg} \mathrm{ha}^{-1}$, nas entrelinhas. $O$ tratamento com controle mecânico consistiu de capinas em faixas de 1,2 $\mathrm{m}$ nas linhas de plantio e roçadas nas entrelinhas. Utilizaram-se 10 espécies arbóreas, plantadas no espaçamento $3,2 \times 1,7 \mathrm{~m}$. Avaliou-se sobrevivência e crescimento em altura das espécies aos 6, 18 e 30 meses após o plantio e o diâmetro ao nível do solo aos 30 meses. Os custos envolvidos na aplicação e na manutenção de cada tratamento, até 30 meses após o plantio, também foram avaliados. A taxa de sobrevivência sofreu pouca influência dos tratamentos utilizados. Em todas as épocas de avaliação do tratamento químico, as 10 espécies florestais obtiveram maior crescimento em altura, comportamento semelhante ao diâmetro ao nível do solo aos 30 meses. O tratamento mecânico apresentou custo de manutenção, aproximadamente, três vezes superior ao tratamento com glifosato.
\end{abstract}

\section{Chemical weed control in forest restoration stands}

\begin{abstract}
This paper aimed to assess the herbicide glyphosate effectiveness in areas dominated by signal grass in forest restoration stands compared to mechanical control. The chemical control consisted in hoeing $1.2 \mathrm{~m}$ row, before planting, and when brachiaria achieved medium height of $30 \mathrm{~cm}$ applied glyphosate herbicide inter-row in $1,44 \mathrm{~kg} \mathrm{ha}^{-1}$. Mechanical control consisted in hoeing $1.2 \mathrm{~m}$ row in planting lines and inter-row mowing. Ten different tree species were planted in a $3.2 \times 1.7 \mathrm{~m}$ spacing. Survival and height growth were evaluated at 6,12, 18 and 30 months after planting and the collar diameter at 30 months. Implementation and maintenance costs for each treatment were also evaluated at 30 months after planting. Survival rate had little influence from control method. Treatment with glyphosate resulted under all evaluations in superior height growth to all evaluated tree species. The mowing maintenance cost approximately three times the chemical method.
\end{abstract}

\section{Introdução}

Com o desmatamento da Mata Atlântica ao longo dos tempos e o avanço da ciência, a partir do século XX se intensificou a discussão sobre a perda da capacidade produtiva de várias áreas que eram cobertas por florestas. Com a necessidade de recomposição da cobertura florestal, a formação de povoamentos florestais se tornou uma prioridade para fins legais e de conservação deste bioma. Entre os métodos disponíveis, a restauração 
através do plantio de mudas tem sido um dos mais utilizados (Magnago et al., 2015).

Devido ao crescimento relativamente lento das espécies arbóreas nativas, comparado às espécies dos gêneros Eucalyptus spp. e Pinus spp., a formação de povoamentos florestais para restauração normalmente apresenta custos relativamente elevados (Brancalion et al., 2016). Fatores como a ocorrência de plantas indesejadas nas áreas de formação, o uso de espécies inadequadas e solos de baixa fertilidade têm contribuído para incrementar os custos da restauração florestal com espécies nativas (Klippel et al., 2015).

Entre os diversos fatores que afetam os custos dos povoamentos de restauração florestal, o controle de plantas daninhas se destaca (Resende \& Leles, 2017). Muitas áreas utilizadas na formação dos povoamentos florestais apresentam histórico de uso de pastagens, com predominância de espécies do gênero Urochloa spp., conhecidas popularmente como braquiárias. Essas espécies, quando comparadas às espécies arbóreas, apresentam maior eficiência no uso de água e alto desempenho fotossintético em condições de altas temperaturas e luminosidade (Pereira et al., 2014). Além disso, possuem elevada capacidade de extrair nutrientes do solo (Medeiros et al., 2016), o que lhes confere maior potencial competitivo. Em função de condições de infestação de espécie(s) espontânea(s) e do método de controle adotado, como roçadas e coroamentos, os custos com controle de plantas daninhas podem representar até $60 \%$ dos gastos com a restauração florestal (Leles et al., 2015).

O controle mecânico tem sido o método convencional adotado na restauração florestal através da capina manual e da roçada. Devido à alta dependência de mão de obra, é necessário o uso de técnicas mais eficazes e com baixo custo, que possam complementar ou substituir o uso de roçadas e capinas. O método químico, através do uso de herbicidas, tem crescido em áreas florestais (Pereira et al., 2015), por apresentar as vantagens de redução das populações das espécies infestantes, o que propicia menor período de convivência e maior oferta de recursos para as espécies florestais (Machado et al., 2012).

No cenário de restauração florestal, a legislação ambiental ainda não é clara quanto ao emprego de herbicidas, não especificando os locais em que a utilização é restrita. Nesse sentido, torna-se importante o aumento de estudos que avaliem o emprego de herbicidas na restauração florestal, podendo subsidiar a tomada de decisão dos produtores rurais e órgãos ambientais.

O glifosato é o herbicida mais utilizado mundialmente no controle de plantas daninhas, na agricultura e na silvicultura (Benbrook, 2016). O glifosato ((N-fosfonometil) glicina) é um herbicida de largo espectro, aplicado em pós-emergência, não seletivo, muito solúvel em água (12 $\left.\mathrm{g} \mathrm{L}^{-1}\right)$ (Maqueda et al., 2017) e apresenta forte retenção pela matriz do solo (Okada et al., 2016).

Portanto, objetivou-se avaliar o controle de braquiária na formação de povoamentos de restauração florestal pelo uso do controle químico com glifosato e do controle mecânico com capinas e roçadas.

\section{Material e métodos}

\section{Caracterização da região e da área experimental}

O experimento foi implantado no município de Bom Jardim, região serrana do Estado do Rio de Janeiro, em área pertencente à Pequena Central Hidrelétrica $(\mathrm{PCH})$ Santa Rosa II. Localiza-se próximo as coordenadas $22^{\circ} 07^{\prime} 21,78^{\prime \prime} \mathrm{S}$ e $42^{\circ} 18^{\prime} 33,95^{\prime \prime} \mathrm{W}$. Apresenta altitude média de $530 \mathrm{~m}$ e regime climático tropical chuvoso, com inverno seco e verão chuvoso, tipo Aw, segundo a classificação de Köppen.

Segundo informações da estação meteorológica de Cordeiro, RJ, a mais próxima ao local do experimento, de janeiro de 2011 a novembro de 2014 a precipitação média anual foi $1.402 \mathrm{~mm}$, com período de maior estiagem entre junho e setembro, e de maior precipitação de novembro a março. A temperatura média anual na região é de $22{ }^{\circ} \mathrm{C}$, com mínima de $16{ }^{\circ} \mathrm{C}$ em julho e máxima de $28^{\circ} \mathrm{C}$ em fevereiro.

Aárea experimental tem histórico de uso de pastagem para pecuária de corte há mais de 30 anos, dominada por espécies forrageiras do gênero Urochloa spp. (braquiárias), com predominância de Urochloa brizantha (Stapf) Webster cv. Marandu e U. decumbens (Stapf.) Webster.

O solo da área foi classificado como Latossolo Vermelho Amarelo Distrófico (Santos et al., 2013), com textura argilo arenosa e $42 \%$ de areia, $55 \%$ de argila e $3 \%$ de silte. A análise de fertilidade (camada de $0-30 \mathrm{~cm}$ ) apresentou: $\mathrm{pH}=4,9 ; \mathrm{P}=0,7 \mathrm{mg} \mathrm{dm}^{-3}$;

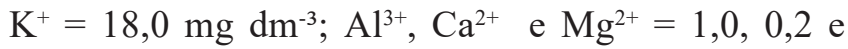
$0,1 \mathrm{cmol}_{\mathrm{c}} \mathrm{dm}^{-3}$, respectivamente, e teor de matéria orgânica de 1,93 dag kg-1. 


\section{Caracterização do experimento}

O experimento foi composto por dois tratamentos, sendo duas técnicas de controle da vegetação herbácea espontânea para formação do povoamento florestal, até 30 meses após o plantio. A primeira técnica foi o controle mecânico, que consistiu na capina manual em faixas de 1,2 m nas linhas de plantio das espécies arbóreas e roçada nas entrelinhas, com roçadeira lateral, sempre que o capim braquiária atingisse altura média de 30 $\mathrm{cm}$. A segunda técnica constituiu no controle químico e coroamento em torno das plantas (raio de $35 \mathrm{~cm}$ aproximadamente).

Para implantação do experimento, inicialmente as linhas de plantio foram capinadas em faixas com 1,20 m de largura e as entrelinhas roçadas apenas como preparo da área para plantio. Em seguida, foram abertas covas de plantio, manualmente, com dimensões de $30 \mathrm{~cm} \mathrm{x}$ $30 \mathrm{~cm}$ x $30 \mathrm{~cm}$ (largura, comprimento e profundidade), adubados com $120 \mathrm{~g}$ de N-P-K (03-24-04) + 15,0\% Ca $+4,7 \% \mathrm{~S}$, misturado à terra retirada das covas. $\mathrm{O}$ plantio foi realizado na primeira semana de novembro.

Aos 2,5 meses após o plantio das mudas arbóreas, aplicou-se a calda à base de glifosato (formulação de sal de isopropilamina de glifosato $480 \mathrm{~g} \mathrm{~L}^{-1}$ ) na dose de $1,44 \mathrm{~kg} \mathrm{ha}^{-1}$ de ingrediente ativo, com uso de pulverizador costal. Novas aplicações ocorreram sempre que o capim braquiária atingiu altura média de $30 \mathrm{~cm}$, sendo realizadas na $1^{\mathrm{a}}$ semana de maio e na $3^{\mathrm{a}}$ semana de dezembro.

O plantio foi realizado em espaçamento $3,2 \times 1,7 \mathrm{~m}$. Foram utilizadas 10 espécies arbóreas (Tabela 1), indicadas por Resende et al. (2017) para a formação de povoamentos florestais no estado do Rio de Janeiro. As mudas foram produzidas em sacos plásticos de $9 \mathrm{~cm}$ x $20 \mathrm{~cm}$ (diâmetro x altura) e na época do plantio apresentavam altura entre 30 e $70 \mathrm{~cm}$, dependendo da espécie.

Cada unidade experimental foi formada por 15 linhas com 10 plantas (uma de cada espécie), englobando área de aproximadamente $820 \mathrm{~m}^{2}$. As duas unidades amostrais foram alocadas uma ao lado da outra, englobando em torno de $1.640 \mathrm{~m}^{2}$. A distribuição das mudas nas covas de plantio, em cada linha, foi igual para as duas unidades experimentais, com as mudas de cada espécie dentro da mesma faixa de altura e de diâmetro de coleto.

Tabela 1. Espécies utilizadas em experimento de diferentes estratégias de controle de Urochloa spp. em área de reflorestamento, no município de Bom Jardim, RJ.

Table 1. Species used in experiment of different control strategies of Urochloa spp. in forest restoration sites, in the municipality of Bom Jardim, RJ.

\begin{tabular}{lccc}
\hline \multicolumn{1}{c}{ Espécie } & Nome popular & Família & Grupo ecológico \\
\hline Anadenanthera macrocarpa (Benth.) Brenan & Angico vermelho & Fabaceae & Pioneiras inicial e/ou secundária \\
Senna multijuga (Rich.) Irwin et Barn. & Pau cigarra & Fabaceae & Pioneira \\
Enterolobium contortisiliquum (Vell.) & Orelha de negro & Fabaceae & Pioneira \\
Peltophorum dubim (Springer.) Taub. & Farinha seca & Fabaceae & Pioneira inicial e/ou secundária \\
Schizolobium parahyba (Vell.) S.F. Blake & Guapuruvu & Fabaceae & Pioneira \\
Cordia trichotoma (Vell.) Arrab. ex Steud. & Louro pardo & Boraginaceae & Pioneira \\
Cytharexyllum myrianthum Cham. & Pau viola & Verbenaceae & Pioneira \\
Guarea guidonia (L.) Sleumer & Carrapeta & Meliaceae & Pioneiras inicial e/ou secundária \\
Schinus terebinthifolius Raddi. & Aroeira pimenteira & Anacardiaceae & Pioneiras inicial e/ou secundária \\
Tibouchina granulosa Cogn. & Quaresmeira & Melastomataceae & Pioneiras inicial e/ou secundária \\
\hline Fonte: Resende et al. (2017) & & &
\end{tabular}

O início da aplicação dos tratamentos ( $\mathrm{T} 1$ - controle mecânico e T2 - controle químico) ocorreu aos 75 dias após o plantio. Nesta época, em T2, foi aplicada a dose de $5 \mathrm{~L} \mathrm{ha}^{-1}$ do herbicida, com pulverizador costal de $20 \mathrm{~L}$, com ponta de pulverização SF-110-015 à pressão de $200 \mathrm{kPa}$. Foi realizado treinamento prévio dos aplicadores para evitar deriva do herbicida, para aplicação com barra de pulverização à altura média de $50 \mathrm{~cm}$ do solo e para proteção das plantas para não ocorrer contato com a calda de herbicida. Além disso, foi utilizada a válvula reguladora de pressão e as aplicações ocorreram em condições ambientais adequadas. 
A dose utilizada foi recomendada com base na bula do herbicida, para as espécies gramíneas predominantes na área e o estádio de desenvolvimento dessas. As aplicações ocorreram entre 8 e $10 \mathrm{~h}$ da manhã, em condições com umidade relativa do ar entre 60 a $80 \%$ e velocidade do vento inferior a $10 \mathrm{~km} \mathrm{~h}^{-1}$. Novas aplicações foram realizadas na $1^{\mathrm{a}}$ semana de maio de 2012 e na $3^{\mathrm{a}}$ semana de dezembro de 2012, quando a braquiária atingiu altura média de $30 \mathrm{~cm}$ e estava, visualmente, em mais de $30 \%$ da superfície do solo.

O controle das formigas cortadeiras iniciou-se aos 40 dias antes do plantio e foi realizado rotineiramente, utilizando iscas granuladas. Replantios foram realizados aos 15 e 30 dias após o plantio, com duas mudas de $A$. macrocarpa e de $S$. parahyba e uma de C. myrianthum. Adubações de cobertura ocorreram aos seis e 12 meses após o plantio, com aplicação de 50 e 100 g de N-P-K (20-05-20) por planta, respectivamente.

\section{Avaliações}

Foram realizadas avaliações de sobrevivência e crescimento em altura (com régua graduada) aos 6, 18 e 30 meses após o plantio. Mediu-se também o diâmetro ao nível do solo, aos 30 meses, com paquímetro digital.

Para realizar o cálculo dos custos totais de cada técnica até os 30 meses após plantio, todas as atividades referentes ao controle de plantas espontâneas e ou daninhas foram listadas e cronometradas. Foi utilizado, como parâmetro, o custo de homem-hora de $\mathrm{R} \$ 12,50$, valor médio praticado pela empresa prestadora do serviço no período em que foi realizado o experimento, que também incluem os custos de transporte, alimentação, encargos sociais, impostos, taxas administrativas, etc.

Para a atividade de roçada, foram acrescentados $20 \%$ no valor da mão de obra, para cobrir custos de aquisição, uso e manutenção da roçadeira e gastos com combustível (gasolina e óleo) do equipamento. No tratamento T2, à atividade de aplicação de herbicida foram acrescentados $8 \%$ no valor da mão de obra, para cobrir custos de aquisição e uso do pulverizador costal e de equipamentos de proteção individual para aplicação de herbicida. Foi utilizado o valor de $\mathrm{R} \$ 22,00 \mathrm{~L}^{-1}$ de Roundup ${ }^{\circledR} \mathrm{NA}$, com base na média de preços desse produto à época, cotado em lojas de produtos agrícolas da região serrana do Estado do Rio de Janeiro e da Zona da Mata de Minas Gerais.

Os resultados foram expressos em custo da atividade por hectare, que inclui o gasto com insumos e mão de obra. Para esse segundo, foi utilizada a equação 1 .

$$
C O=\frac{T E^{*} H R^{*} 10000}{A A} * k
$$

Em que: $\mathrm{CO}=$ custo da operação $\left(\mathrm{R} \$ \mathrm{ha}^{-1}\right) ; \mathrm{TE}=$ tempo de execução da operação (h); HR = custo homem-hora = $\mathrm{R} \$ 12,50 ; \mathrm{AA}=$ área da parcela; $\mathrm{K}=$ constante considerando $20 \%$ do tempo como descanso $=1,2$.

\section{Análises estatísticas}

Os dados de altura, nas três idades, e diâmetro ao nível do solo aos 30 meses foram submetidos ao teste $\mathrm{t}$, de amostras independentes, adotando-se o nível de significância de 5\%. Para todas as análises, foi utilizado o software Sistema de Análise Estatística e Genética (SAEG, 2007).

\section{Resultados}

Em ambos os tratamentos, a taxa de sobrevivência aos 30 meses foi superior a $80 \%$. Apenas para as espécies Cytharexyllum myrianthum, Cordia trichotoma, Guarea guidonia e Schizolobium parahyba a sobrevivência foi inferior a $80 \%$, principalmente no tratamento de controle químico. As taxas de sobrevivência das espécies florestais aos 6, 18 e 30 meses após o plantio estão apresentadas na Tabela 2.

Ao analisar a Tabela 3, constata-se que a altura média das 10 espécies, em todas as idades avaliadas, apresentaram diferenças, sendo que as plantas arbóreas do tratamento que recebeu o controle químico apresentaram maior média.

As espécies que apresentaram maior crescimento foram A. macrocarpa, S. multijuga, E. contortisiliquum, $P$. dubim e $S$. parahyba, principalmente no tratamento com o herbicida. Apenas para $C$. myrianthum, $C$. trichotoma e G. guidonia não houve efeito significativo em altura, em nenhuma das idades avaliadas. Aos 30 meses, o crescimento médio em altura do conjunto formado pelas 10 espécies foi, aproximadamente, $56 \%$ superior no tratamento usando controle químico.

Ao analisar o crescimento em diâmetro ao nível do solo, aos 30 meses após o plantio para o conjunto das 10 espécies arbóreas (Figura 1), constata-se o mesmo padrão de resposta em altura, com favorecimento do tratamento com aplicação de glifosato. Dentre as 10 espécies, verifica-se que seis apresentaram crescimento significativamente superior no tratamento químico. 
Tabela 2. Sobrevivência (\%), em três idades após o plantio, de 10 espécies arbóreas, sob dois métodos de controle de plantas herbáceas em área de restauração florestal, no município de Bom Jardim, RJ.

Table 2. Survival (\%), at three ages after planting, of 10 tree species, under two methods of control of herbaceous plants in forest restoration sites, in the municipality of Bom Jardim, RJ.

\begin{tabular}{|c|c|c|c|c|c|c|}
\hline \multirow{2}{*}{ Espécies } & \multicolumn{2}{|c|}{--- 6 meses --- } & \multicolumn{2}{|c|}{--- 18 meses --- } & \multicolumn{2}{|c|}{--- 30 meses --- } \\
\hline & T1 & T2 & T1 & T2 & T1 & $\mathbf{T 2}$ \\
\hline $\begin{array}{l}\text { Anadenanthera } \\
\text { macrocarpa }\end{array}$ & 100,0 & 93,3 & 100,0 & 93,3 & 93,3 & 93,3 \\
\hline Cordia trichotoma & 100,0 & 88,8 & 77,7 & 77,7 & 72,5 & 72,2 \\
\hline $\begin{array}{l}\text { Cytharexyllum } \\
\text { myrianthum }\end{array}$ & 100,0 & 81,0 & 100,0 & 81,0 & 95,2 & 71,4 \\
\hline $\begin{array}{l}\text { Enterolobium } \\
\text { contortisiliquum }\end{array}$ & 100,0 & 100,0 & 100,0 & 100,0 & 100,0 & 100,0 \\
\hline Guarea guidonia & 95,2 & 95,2 & 85,7 & 71,4 & 76,2 & 71,4 \\
\hline $\begin{array}{l}\text { Peltophorum } \\
\text { dubim }\end{array}$ & 96,6 & 91,7 & 87,5 & 91,7 & 83,3 & 91,7 \\
\hline $\begin{array}{l}\text { Schinus } \\
\text { terebinthifolius }\end{array}$ & 96,6 & 100,0 & 96,6 & 100,0 & 96,6 & 100,0 \\
\hline $\begin{array}{l}\text { Schizolobium } \\
\text { parahyba }\end{array}$ & 100,0 & 75,0 & 95,8 & 75,0 & 95,8 & 75,0 \\
\hline Senna multijuga & 100,0 & 90,4 & 90,4 & 85,7 & 90,5 & 85,7 \\
\hline $\begin{array}{l}\text { Tibouchina } \\
\text { granulosa }\end{array}$ & 91,6 & 95,8 & 91,6 & 95,8 & 91,6 & 95,8 \\
\hline Média das especies & 98,0 & 91,1 & 92,5 & 87,1 & 89,5 & 82,8 \\
\hline
\end{tabular}

Figura 1. Diâmetro ao nível do solo, aos 30 meses após o plantio, de 10 espécies arbóreas implantadas em experimento de restauração florestal, sob dois métodos de controle de plantas herbáceas, no município de Bom Jardim, RJ. Para cada espécie, letras iguais entre tratamentos significa que estes não diferem entre si a $5 \%$ pelo teste $\mathrm{t}$ de amostras independentes. As barras representam o desvio padrão.

Figure 1. At soil level at 30 months after planting of 10 tree species implanted in a forest restoration experiment, under two herbaceous control methods, in the municipality of Bom Jardim, RJ. The same letter between treatments shows similar results by $\mathrm{t}$ test of independent samples, considering $5 \%$ of probability. Bars represent standard deviation.
Tabela 3. Altura (m), em três idades após o plantio, de 10 espécies arbóreas, sob dois métodos de controle de plantas herbáceas em área de restauração florestal, no município de Bom Jardim, RJ.

Table 3. Height (m), at three ages after planting, of 10 tree species, under two methods of control of herbaceous plants in a forest restoration sites, in the municipality of Bom Jardim, RJ.

\begin{tabular}{|c|c|c|c|c|c|c|}
\hline \multirow{2}{*}{ Espécie } & \multicolumn{2}{|c|}{--- 6 meses -- } & \multicolumn{2}{|c|}{--- 18 meses -- } & \multicolumn{2}{|c|}{--- 30 meses --- } \\
\hline & T1 & T2 & T1 & T2 & T1 & T2 \\
\hline $\begin{array}{l}\text { A.macrocarpa } \\
(30 \mathrm{a} 40 \mathrm{~cm})\end{array}$ & $\begin{array}{c}0,77 \\
(0,25)\end{array}$ & $\begin{array}{l}1,06^{*} \\
(0,23)\end{array}$ & $\begin{array}{c}1,52 \\
(0,54)\end{array}$ & $\begin{array}{l}2,48^{*} \\
(0,65)\end{array}$ & $\begin{array}{c}2,70 \\
(0,61)\end{array}$ & $\begin{array}{l}3,70 * \\
(1,18)\end{array}$ \\
\hline $\begin{array}{l}\text { C. trichotoma } \\
(30 \mathrm{a} 40 \mathrm{~cm})\end{array}$ & $\begin{array}{c}0,58 \\
(0,08)\end{array}$ & $\begin{array}{l}0,63^{\mathrm{ns}} \\
(0,21)\end{array}$ & $\begin{array}{c}0,64 \\
(0,11)\end{array}$ & $\begin{array}{l}1,08^{\text {ns }} \\
(0,48)\end{array}$ & $\begin{array}{c}1,00 \\
(0,41)\end{array}$ & $\begin{array}{l}1,52^{\text {ns }} \\
(0,89)\end{array}$ \\
\hline $\begin{array}{l}\text { C. myrianthum } \\
(25 \mathrm{a} 40 \mathrm{~cm})\end{array}$ & $\begin{array}{c}0,51 \\
(0,14)\end{array}$ & $\begin{array}{l}0,53^{\text {ns }} \\
(0,27)\end{array}$ & $\begin{array}{c}0,88 \\
(0,32)\end{array}$ & $\begin{array}{c}1,1^{\text {ns }} \\
(0,62)\end{array}$ & $\begin{array}{c}1,60 \\
(0,59)\end{array}$ & $\begin{array}{c}1,80^{\text {ns }} \\
(1,1)\end{array}$ \\
\hline $\begin{array}{l}\text { E. contortisiliquum } \\
(50 \text { a } 70 \mathrm{~cm})\end{array}$ & $\begin{array}{l}1,38 \\
(0,42)\end{array}$ & $\begin{array}{l}1,54^{*} \\
(0,47)\end{array}$ & $\begin{array}{l}1,99 \\
(0,33)\end{array}$ & $\begin{array}{l}2,82^{*} \\
(0,82)\end{array}$ & $\begin{array}{c}2,70 \\
(0,86)\end{array}$ & $\begin{array}{l}3,50 * \\
(0,99)\end{array}$ \\
\hline $\begin{array}{l}\text { G. guidonia } \\
(30 \mathrm{a} 40 \mathrm{~cm})\end{array}$ & $\begin{array}{c}0,62 \\
(0,13)\end{array}$ & $\begin{array}{l}0,53^{\text {ns }} \\
(0,21)\end{array}$ & $\begin{array}{c}0,74 \\
(0,17)\end{array}$ & $\begin{array}{l}0,86^{\text {ns }} \\
(0,35)\end{array}$ & $\begin{array}{c}1,20 \\
(0,35)\end{array}$ & $\begin{array}{l}1,20^{\text {ns }} \\
(0,45)\end{array}$ \\
\hline $\begin{array}{l}\text { P. dubim } \\
(25 \text { a } 35 \mathrm{~cm})\end{array}$ & $\begin{array}{c}0,50 \\
(0,14)\end{array}$ & $\begin{array}{l}0,92 * \\
(0,34)\end{array}$ & $\begin{array}{c}0,88 \\
(0,35)\end{array}$ & $\begin{array}{l}2,64 * \\
(0,82)\end{array}$ & $\begin{array}{c}1,70 \\
(0,54)\end{array}$ & $\begin{array}{l}3,60^{*} \\
(0,91)\end{array}$ \\
\hline $\begin{array}{l}\text { S. terebinthifolius } \\
(30 \mathrm{a} 45 \mathrm{~cm})\end{array}$ & $\begin{array}{c}0,66 \\
(0,20)\end{array}$ & $\begin{array}{l}0,97^{*} \\
(0,33)\end{array}$ & $\begin{array}{c}1,08 \\
(0,34)\end{array}$ & $\begin{array}{l}2,05^{*} \\
(0,52)\end{array}$ & $\begin{array}{c}1,90 \\
(0,58)\end{array}$ & $\begin{array}{l}3,00^{*} \\
(0,81)\end{array}$ \\
\hline $\begin{array}{l}\text { S. parahyba } \\
(40 \text { a } 50 \mathrm{~cm})\end{array}$ & $\begin{array}{c}0,69 \\
(0,21)\end{array}$ & $\begin{array}{l}1,23^{*} \\
(0,44)\end{array}$ & $\begin{array}{c}1,09 \\
(0,44)\end{array}$ & $\begin{array}{l}2,92 * \\
(0,98)\end{array}$ & $\begin{array}{c}1,80 \\
(0,71)\end{array}$ & $\begin{array}{l}4,60^{*} \\
(1,27)\end{array}$ \\
\hline $\begin{array}{l}\text { S. multijuga } \\
(50 \text { a } 60 \mathrm{~cm})\end{array}$ & $\begin{array}{c}0,82 \\
(0,22)\end{array}$ & $\begin{array}{l}1,20^{*} \\
(0,43)\end{array}$ & $\begin{array}{l}1,23 \\
(0,61)\end{array}$ & $\begin{array}{l}2,67 * \\
(0,66)\end{array}$ & $\begin{array}{c}2,10 \\
(0,77)\end{array}$ & $\begin{array}{l}3,70 * \\
(0,91)\end{array}$ \\
\hline $\begin{array}{l}\text { T. granulosa } \\
(40 \text { a } 50 \mathrm{~cm})\end{array}$ & $\begin{array}{c}0,77 \\
(0,22)\end{array}$ & $\begin{array}{l}1,00^{*} \\
(0,14)\end{array}$ & $\begin{array}{c}1,14 \\
(0,36)\end{array}$ & $\begin{array}{l}1,81^{*} \\
(0,26)\end{array}$ & $\begin{array}{c}2,00 \\
(0,32)\end{array}$ & $\begin{array}{l}2,60^{*} \\
(0,49)\end{array}$ \\
\hline $\begin{array}{l}\text { Média das } \\
\text { espécies }\end{array}$ & $\begin{array}{c}0,73 \\
(0,36)\end{array}$ & $\begin{array}{l}0,96 * \\
(0,47)\end{array}$ & $\begin{array}{c}1,11 \\
(0,66)\end{array}$ & $\begin{array}{l}2,04 * \\
(1,08)\end{array}$ & $\begin{array}{c}1,87 \\
(0,99)\end{array}$ & $\begin{array}{l}2,92 * \\
(1,34)\end{array}$ \\
\hline
\end{tabular}

T1 = controle mecânico; T2 = predominância do controle químico com glifosato. $*=$ diferença significativa a $5 \%$ pelo teste $\mathrm{t}$ de amostras independentes; ${ }^{\text {ns }}=$ não significativo. Números entre parênteses referem-se ao desvio padrão. Os valores abaixo do nome de cada espécie referem-se ao intervalo de altura que as mudas apresentavam no dia do plantio.

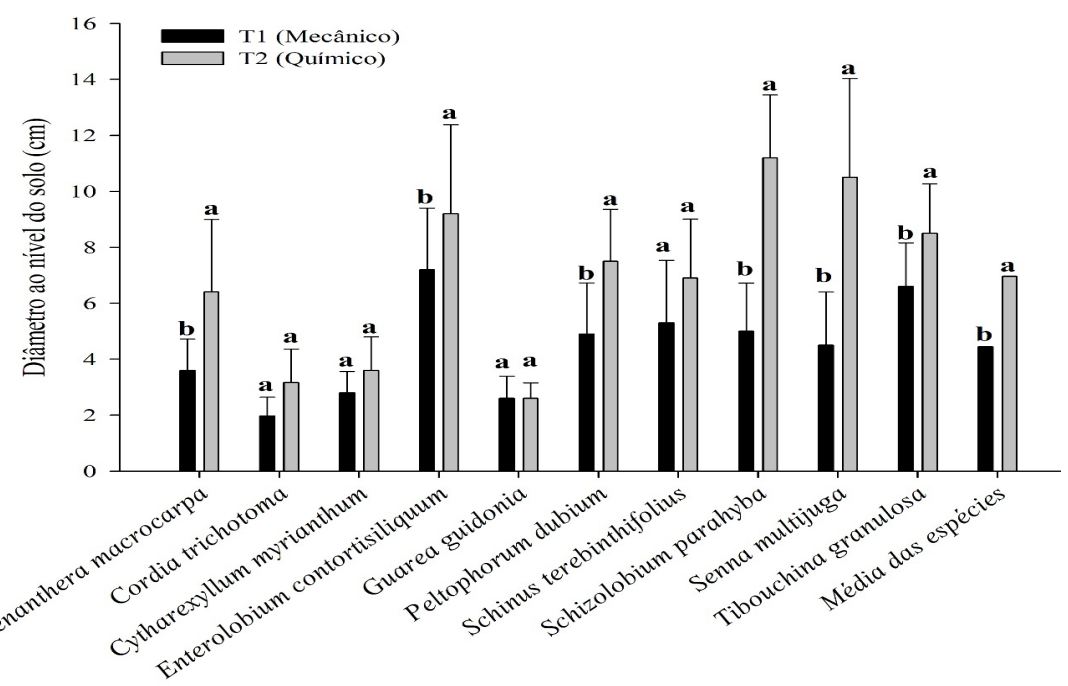


Constata-se, pela Tabela 4, que os custos com controle mecânico da vegetação herbácea, predominantemente com espécies de Urochloa sp., foram quase três vezes superiores, em comparação ao tratamento com aplicação do herbicida.

Com o controle mecânico, foram necessárias cinco operações de capina em faixas de 1,2 m e sete de roçada nas entrelinhas de plantio. Estas ações aconteceram em oito momentos, para manter o controle das plantas espontâneas no tratamento mecânico, até aos 30 meses após o plantio.

No tratamento químico, entre dois a 30 meses após o plantio, foram necessárias cinco intervenções de controle de plantas espontâneas, sendo que em apenas três momentos houve necessidade de aplicação de calda com glifosato. Essa atividade foi encerrada aos 13 meses (Tabela 4).

Tabela 4. Atividades realizadas, por data, e seus custos em dois métodos de controle de plantas herbáceas para formação de reflorestamentos para restauração florestal, no município de Bom Jardim, RJ.

Table 4. Activities carried out, by date, and their costs in two herbaceous plant control methods for formation of forest reforestation, in the municipality of Bom Jardim, RJ.

\begin{tabular}{|c|c|c|c|c|}
\hline \multirow{2}{*}{$\begin{array}{c}\text { Data } \\
\text { (d/m/ano) }\end{array}$} & \multicolumn{2}{|c|}{ Controle mecânico (roçadas e capinas) } & \multicolumn{2}{|c|}{ Predominância de controle químico } \\
\hline & Atividade(s) & Custo (RS ha-1) & Atividade(s) & Custo (RS ha-1) \\
\hline $18 / 01 / 12$ & Roçada* e capina** & 983,80 & Aplicação glifosato*** e capina*** & 756,80 \\
\hline $02 / 05 / 12$ & Roçada* & 694,44 & Aplicação glifosato*** & 357,60 \\
\hline $20 / 12 / 12$ & Roçada* e capina** & $1.244,20$ & Aplicação glifosato*** e capina** & 787,60 \\
\hline $05 / 03 / 13$ & Roçada* e capina** & $1.087,90$ & ---------------------------------- & ---------- \\
\hline $19 / 06 / 13$ & Roçada* & 520,80 & Roçada de moitas de braquiária & 277,80 \\
\hline $18 / 10 / 13$ & Capina** & 374,20 & ----------------------------------- & --------- \\
\hline $04 / 02 / 14$ & Roçada* e capina** & $1.082,18$ & Roçada de moitas de braquiária & 232,60 \\
\hline $02 / 05 / 14$ & Roçada* & 694,40 & --------------------------------- & --------- \\
\hline \multicolumn{2}{|r|}{ Custo Total } & $6.681,92$ & Custo total & $2.412,40$ \\
\hline
\end{tabular}

* = com roçadeira lateral entre as "linhas" das plantas arbóreas; ** = com enxada em faixa nas linhas de plantio de 1,2 m de largura; $* * *=$ com pulverizador costal, na dose de 5,0 $\mathrm{L}$ de herbicida a base de glifosato ha ${ }^{-1}$.

\section{Discussão}

Segundo Art. 8, da Resolução INEA nº 89, de 03 de junho de 2014 do Instituto Estadual do Ambiente (INEA) (2014), do Estado do Rio de Janeiro, povoamentos florestais para restauração florestal com espécies arbóreas nativas com sobrevivência superior a $80 \%$, aos quatro anos após o plantio, não necessitam de replantios. Assim, os dois tratamentos em que se aplicou o controle das plantas espontâneas atendem a este quesito, pois aos 2,5 anos após plantio (última avaliação) apresentaram média de taxa de sobrevivência de $89,5 \%$ (controle mecânico) e 82,8\% (controle químico). Acredita-se que nessa idade as plantas já estejam adaptadas ao ambiente, com crescimento em altura (Tabela 3) o que dificulta a supressão pelas plantas infestantes e que dificilmente ocorrerá aumento do índice de mortalidade.

Para Schizolobium parahyba houve diferenças de mais de $20 \%$ de sobrevivência entre os dois tratamentos. Dentre as possibilidades para explicar este comportamento, podemos considerar que algumas plantas desta espécie podem ter sofrido com deriva da calda do glifosato, apesar dos cuidados tomados. Outra possibilidade é que o crescimento rápido das plantas do tratamento 2 (Tabela 3), em especial de Schinus terebenthifolius (vizinhas a $S$. parahyba nas linhas de plantio) possa ter prejudicado, tendo em vista que $S$. parahyba também é uma espécie pioneira (Carvalho, 2003) e precisa de muita luz para seu crescimento. Com isso, é possível que algumas plantas das espécies arbóreas tenham sido suprimidas e morrido já aos seis meses após o plantio.

Em função da alta variabilidade genética das espécies nativas, a resposta à deriva de glifosato é bastante variável (Pereira et al., 2015). Florencia et al. (2017) concluíram que, enquanto algumas espécies não alvo morrem com sub-doses de glifosato, algumas sobrevivem com efeitos moderados e outras são consideradas tolerantes. 
Pereira et al. (2015), estudando deriva de glifosato no crescimento de Psidium cattleyanum, Citharexylum myrianthum e Cedrela odorata, observaram que as duas primeiras espécies foram tolerantes a todas as doses de glifosato, enquanto que as plantas de Cedrela odorata foram bastante sensíveis à aplicação do herbicida.

Para outros herbicidas, Brancalion et al. (2009) observaram que plantas de Senna multijuga, Guazuma ulmifolia e Croton urucurana, submetidas à aplicação de calda com setoxidim, isoxaflutol e bentazon, apresentaram sintomas de fitotoxicidade, porém estes não foram suficientes para causar a morte das plantas.

É importante frisar que a deriva deve ser sempre evitada, com conhecimento dos fatores que influenciam a pulverização em cada local, tais como clima (umidade e vento), o princípio ativo e a dose do herbicida, equipamento e treinamento do operador, adotando-se a tecnologia de aplicação adequada.

Observa-se que C. trichotoma, na avaliação de 18 e 30 meses, apresentou sobrevivência inferior a 80\% (Tabela $2)$. Isto provavelmente ocorreu por essa espécie ser relativamente exigente em relação ao solo e que deve ser plantada em solos de fertilidade química relativamente média a alta (Carvalho, 2003). Segundo Furtini Neto (2000), o solo no local onde esse experimento foi instalado pode ser considerado de fertilidade mediana a fraca.

O maior crescimento em altura (Tabela 3), nas unidades amostrais do tratamento com aplicação de glifosato, ocorreu, provavelmente, devido à redução da população das plantas infestantes, o que reduz o período em que estas e as espécies arbóreas coexistiram. Como resultado, há maior oferta de fatores de crescimento, como água, luz e nutrientes, e evitam-se possíveis efeitos de compostos alelopáticos, liberados por indivíduos de Urochloa sp. (Souza et al., 2003), resultando em condições mais favoráveis ao crescimento das espécies nativas. Pelo método mecânico, a roçada possui a capacidade reduzida em limitar o crescimento das plantas infestantes e, não ocorrendo o fechamento do dossel do povoamento, essas espécies podem se restabelecer e competir com as espécies arbóreas.

Os resultados indicam que a largura da faixa capinada, adotada nesse estudo, não foi suficiente para a eliminação dos efeitos da matocompetição, afetando negativamente o ritmo de crescimento das espécies arbóreas implantadas. Toledo et al. (2003) testaram larguras na capina em faixas, na linha de plantio, na formação de povoamento de Eucalyptus urophylla x $E$. grandis e concluíram que houve efeito apenas quando a faixa capinada apresentava pelo menos 2,0 $\mathrm{m}$ de largura. Resultados semelhantes foram obtidos por Maciel et al. (2011), adotando capina na forma de coroamento no crescimento de plantas de Schinus terebinthifolius e de Inga fagifolia, em que o melhor crescimento inicial foi observado quando empregou-se coroamento em diâmetro de 2,0 m.

As plantas que apresentaram maior diferença entre os tratamentos e de crescimento foram as das espécies $A$. macrocarpa, S. multijuga, E. contortisiliquum, P. dubim e $S$. parahyba, todas pertencentes à família Fabaceae. $\mathrm{O}$ crescimento rápido dos indivíduos de espécies dessa família pode ser atribuído à sua capacidade de adaptação aos solos relativamente pobres em nutrientes e clima com período seco definido, como o local de realização deste trabalho.

Entre as espécies com menor crescimento, durante a condução do experimento, observou-se que muitos indivíduos de C. myrianthum secaram (parte superior da planta, incluindo ramos e folhas) ao final da estação seca e rebrotaram na estação chuvosa, acarretando variação dos dados dendrométricos, o que pode explicar o menor crescimento de indivíduos dessa espécie. G. guidonia e C. myrianthum, consideradas espécies secundárias (Carvalho, 2003), além do menor crescimento em altura e taxa de sobrevivência inferior a $80 \%$ (Tabela 2), apresentaram menor diâmetro aos 30 meses (Figura 1), indicando que essas espécies, aparentemente, não se adaptaram às condições edafoclimáticas do local.

O maior custo do controle das plantas daninhas no tratamento com controle mecânico, até 30 meses após o plantio, foi devido à maior quantidade de intervenções, que demandaram mais mão de obra (Tabela 4). A rebrota e o crescimento das espécies indesejadas, promovidos pela roçada, levam ao maior número de intervenções.

Em estudo avaliando a frequência necessária das atividades de coroamento e roçada na formação de povoamentos puros de Acacia mearnsii, Eucalyptus grandis, Mimosa scabrella e Ateleia glazioviana, em área com predominância de braquiária, Eloy et al. (2014) concluíram que são necessárias intervenções de roçada a cada dois meses, em todos os casos avaliados. É importante ressaltar que o intervalo dessas intervenções não é regular e depende das chuvas, sendo que nos períodos chuvosos são necessárias mais roçadas e/ou coroamentos. 
No presente estudo, os custos de intervenções foram maiores no primeiro ano de condução do experimento, período em que as espécies nativas são mais susceptíveis à competição e não há formação de dossel, favorecendo o crescimento das espécies daninhas. Os resultados estão de acordo com Silva et al. (2009), que mencionam que o tratamento químico apresenta menor dependência de mão de obra em quantidade. Entretanto, demanda mão de obra treinada para a correta aplicação do herbicida, além de equipamentos de proteção individual. Ressalta-se que um dos principais problemas de uso de herbicidas com uso de pulverizador costal é a tecnologia de aplicação, sendo imprescindível treinamento dos aplicadores e conhecimento dos fatores climáticos que interferem na eficiência da aplicação.

Com os resultados obtidos nesse estudo, é possível inferir que o método químico com uso de glifosato é mais vantajoso na formação de povoamentos com espécies nativas, quando comparado a capina em faixas de 1,2 $m$ e roçadas nas entrelinhas, quanto ao crescimento das espécies arbóreas e os custos de manutenção.

Cabe destacar a preocupação ambiental com uso desses produtos e a necessidade de estudos sobre os efeitos negativos dos herbicidas. Acredita-se que esses estudos são essenciais para o estabelecimento de normas para uso de glifosato em restauração florestal, devido à sua eficiência no controle de espécies infestantes. Como destacam Moraes \& Rossi (2010), estudos detalhados com glifosato em diferentes condições ambientais são determinantes para o correto uso desse produto, diminuindo os riscos de danos ambientais diretos ou indiretos. Além disso, como destacam Nieweglowski Filho et al. (2014), deve-se utilizar corretamente a tecnologia de aplicação, pois quando isso é ignorado a eficiência do controle químico é comprometida, podendo aumentar o banco de sementes das espécies não controladas, contaminação ambiental, perda do produto comercial, além de aumentos dos custos do uso do controle químico.

\section{Conclusão}

O controle de plantas herbáceas, em área com predominância de braquiária, com o tratamento glifosato proporcionou maior crescimento das plantas das espécies arbóreas e o menor custo no controle das plantas herbáceas, em relação ao tratamento com roçada nas entrelinhas e capinas nas faixas.

\section{Agradecimentos}

À PCH Santa Rosa S/A por ceder a área, apoio e mão de obra para realização do trabalho.

\section{Referências}

Benbrook, C. M. Trends in glyphosate herbicide use in the United States and globally. Environmental Sciences Europe, v. 28, p. 1-15, 2016. DOI: 10.1186/s12302-016-0070-0.

Brancalion, P. H. S. et al. Seletividade dos herbicidas setoxidim, isoxaflutol e bentazon a espécies arbóreas nativas. Pesquisa Agropecuária Brasileira, v. 44, n. 3, p. 251-257, 2009.

Brancalion, P. H. S. et al. Balancing economic costs and ecological outcomes of passive and active restoration in agricultural landscapes: the case of Brazil. Biotropica, v. 48, n. 6, p. 856-867, 2016. DOI: 10.1111/btp. 12383 .

Carvalho, P. E. C. (Ed.) Espécies arbóreas brasileiras. Brasília, DF: Embrapa Informação Tecnológica; Colombo: Embrapa Florestas, 2003. v. 1. 1.039 p.

Eloy, E. et al. Período adequado de controle de plantas invasoras em plantios florestais. Revista Ciência da Madeira, v. 5, n. 2, p. 80-84, 2014. DOI: 10.12953/2177-6830.v05n02a01.

Florencia, F. M. et al. Effects of the herbicide glyphosate on non-target plant native species from Chaco forest (Argentina). Ecotoxicology and Environmental Safety, v. 144, n. 1, p. 360-368, 2017. DOI: 10.1016/j.ecoenv.2017.06.049.

Furtini Neto, A. E. et al. Fertilização em reflorestamento com espécies nativas. In: Gonçalves, J. L. M. \& Benedetti, V. (Ed.). Nutrição e fertilização florestal. Piracicaba: IPEF, 2000. p. 352-383.

Instituto Estadual do Ambiente. Resolução INEA n ${ }^{\circ}$ 89, de 03 de junho de 2014. Diário Oficial do Estado do Rio de Janeiro, Rio de Janeiro, 5 jun. 2014.

Klippel, V. H. et al. Avaliação de métodos de restauração florestal de Mata de Tabuleiros-ES. Revista Árvore, v. 39, n. 1, p. 69-79, 2015. DOI: 10.1590/0100-67622015000100007.

Leles P. S. S. et al. Influências do espaçamento de plantio na restauração florestal. In: Leles, P. S. S. \& Oliveira Neto, S. N. (Ed.). Restauração florestal e a Bacia do Rio Guandu. Seropédica: Edur, 2015. p. 107-140.

Maciel, C. D. G. et al. Coroamento no controle de plantas daninhas e desenvolvimento inicial de espécies florestais nativas. Semina: Ciências Agrárias, v. 32, n. 1, p. 119-128, 2011.

Machado, V. M. et al. Controle químico e mecânico de plantas daninhas em áreas em recuperação. Revista Brasileira de Herbicidas, v. 11, n. 2, p. 139-147, 2012. DOI: 10.7824/rbh. v11i2.153.

Magnago, L. F. S. et al. Modelos de restauração florestal. In: Leles, P. S. S. \& Oliveira Neto, S. N. (Ed.). Restauração florestal e a Bacia do Rio Guandu. Seropédica: Edur, 2015. p. 49-70. 
Maqueda, C. et al. Behaviour of glyphosate in a reservoir and the surrounding agricultural soils. Science of the Total Environment, v. 593-594, n. 1, p. 787-795, 2017. DOI: 10.1016/j. scitotenv.2017.03.202.

Medeiros, W. N. et al. Crescimento inicial e concentração de nutrientes em clones de Eucalyptus urophylla x Eucalyptus grandis sob interferência de plantas daninhas. Ciência Florestal, v. 26, n. 1, p. 147-157, 2016. DOI: 10.5902/1980509821099.

Moraes, P. V. D. \& Rossi, P. Comportamento ambiental do glyphosate. Revista Scientia Agraria Paranaensis, v. 9, n. 3, p. 22-35, 2010.

Nieweglowski Filho, M. et al. Controle químico de plantas daninhas utilizando diferentes pontas de pulverização. Scientia Agraria, v. 15, n. 1, p. 33-37, 2014. DOI: 10.5380/rsa.v15i1.41097.

Okada, E. et al. Adsorption and mobility of glyphosate in different soils under no-till and conventional tillage. Geoderma, v. 263, n. 1, p. 178-85, 2016. DOI: 10.1016/j.geoderma.2015.09.009.

Pereira, M. R. R. et al. Subdoses de glyphosate no desenvolvimento de espécies arbóreas nativas. Biosciense Journal, v. 31, n. 2, p. 326332, 2015. DOI: 10.14393/bj-v31n2a2015-21924.

Pereira, F. C. et al. Interferência de plantas daninhas: conceitos e exemplos na cultura do eucalipto. Journal of Agronomic Sciences, v. 3, n. especial, p. 236-255, 2014.
Resende, A. S. \& Leles, P. S. S. O problema do controle de plantas daninhas na restauração florestal.In: (Ed.). Controle de plantas daninhas em restauração florestal. Seropédica: Embrapa Agrobiologia, 2017. p. 13-27.

Resende et al. Características e expectativa de crescimento de espécies florestais nativas da Mata Atlântica recomendadas para plantios de restauração florestal em função da posição da paisagem de plantio. In: Resende, A. S. \& Leles, P. S. S. (Ed.) Controle de plantas daninhas em restauração florestal. Seropédica: Embrapa Agrobiologia, 2017. p. 100-107.

Santos, H. G. et al. Sistema brasileiro de classificação de solos. Brasília, DF: Embrapa, 2013. 353 p.

Saeg: sistema para análises estatísticas. Saeg versão 9.1. 2007. Disponível em: $<$ http://arquivo.ufv.br/saeg/download.htm $>$. Acesso em: 22 nov. 2017.

Silva, A. A. et al. Métodos de controle de plantas daninhas. In: Silva, A. A. \& Silva, J. F. (Ed.). Tópicos em manejo de plantas daninhas. Viçosa, MG: Ed da UFV, 2009. p. 63-81.

Souza, L. S. et al. Efeito alelopático de plantas daninhas e concentrações de capim-braquiária (Brachiaria decumbens) no desenvolvimento inicial de eucalipto (Eucalyptus grandis). Planta Daninha, v. 21, n. 3, p. 343-354, 2003.

Toledo, R. E. B. et al. Faixas de controle de plantas daninhas e seus reflexos no crescimento de plantas de eucalipto. Scientia Forestalis, n. 64, p. $78-92,2003$. 